\title{
Glucose-negative Mutants of Pachysolen tannophilus
}

\author{
By D. N. WEDLOCK, A. P. JAMES $†$ AND R. J. THORNTON* \\ Microbiology and Genetics Department, Massey University, Palmerston North, New Zealand
}

(Received 4 July 1988; revised 24 January 1989; accepted 28 March 1989)

\begin{abstract}
Mutants of the yeast Pachysolen tannophilus, exhibiting decreased ability to utilize D-glucose as the sole carbon source, were obtained by selecting for resistance to 2-deoxyglucose. Enzyme studies confirmed that these strains are defective in the hexose-phosphorylating enzymes and are unable to phosphorylate D-glucose to D-glucose 6-phosphate. The results confirmed the presence of two hexokinases, $\mathrm{A}$ and $\mathrm{B}$, with ratios of $\mathrm{D}$-glucose to $\mathrm{D}$-fructose phosphorylation activity of $1.3 / 1.0$ and $3.0 / 1.0$, respectively, and a D-glucose-specific glucokinase. The behaviour of a hexose-negative strain, able to ferment D-xylose in the presence of D-glucose, is described.
\end{abstract}

\section{INTRODUCTION}

The yeast Pachysolen tannophilus has the ability to ferment hexose and pentose sugars to ethanol. It has, therefore, potential use in the production of ethanol from lignocellulose hydrolysates which are comprised of a mixture of hexose and pentose sugars. Utilization of D-xylose, the major pentose in lignocellulose hydrolysates, by $P$. tannophilus is subject to hexose catabolite repression (Slininger et al., 1987; Bicho et al., 1988). P. tannophilus has low ethanol tolerance and the ethanol produced from the hexoses in lignocellulose hydrolysates prevents the complete utilization of D-xylose. Mutations which affect the hexokinase and glucokinase enzyme activities of $P$. tannophilus should result in hexose-negative strains. D-Xylose utilization by hexose-negative strains should be unaffected since the initial metabolism of $\mathrm{D}$-xylose follows a different pathway from that of D-glucose and other hexoses (Maleszka et al., 1983; Slininger $e t$ al., 1987). Glucose-negative mutants could be used to ferment the xylose component of hydrolysates and a more ethanol-tolerant yeast, e.g. Saccharomyces cerevisiae used subsequently to ferment the hexose sugars. Hexokinase and glucokinase mutants of Saccharomyces cerevisiae have been isolated by selecting for resistance to the toxic analogue of D-glucose, 2-deoxyglucose (Maitra, 1970; Lobo \& Maitra, 1977a,b). This paper reports the isolation, by resistance to 2-deoxyglucose, and characterization of hexokinase- and glucokinase-defective mutants of $P$. tannophilus which are unable to grow on D-glucose as sole carbon source. The characteristics of these mutants in the fermentation of mixtures of D-glucose and D-xylose are also described.

\section{METHODS}

Yeast strains. The 'glucose-negative' strains described in this study were derived from Pachysolen tannophilus P17-1A, a methionine-requiring auxotroph of NRRL Y-2460. Strain P471-5D ade2 was used in genetic crosses with several of the glucose-negative strains. P444-3D, a wild-type segregant, was used for comparison with the mutants in enzyme assays and growth/sugar utilization experiments.

Media. The medium for vegetative growth contained yeast nitrogen base (YNB), either supplemented with amino acids or minimal. The complete composition $(\%, w / v)$ was yeast nitrogen base (Difco) (0.67), agar (Difco) (2) and either D-xylose (2), D-glucose (2), D-mannose (2) or D-fructose (2) as the carbon source. For hybridization of haploid strains, mait extract medium (YM-YE) was used; it contained (\%,w/v), yeast extract (Difco) (1), malt extract (Difco) (1), glucose (0.4), agar (Difco) (2), pH 5.0. The media for the determination of growth and sugar utilization in liquid culture contained $0.67 \%$ YNB and $2 \%(w / v)$ of the appropriate carbon source or a $2 \% / 2 \%$

† Present address: National Research Council, Ottawa, Canada. 
mixture of two carbon sources. Strains were grown in yeast extract peptone medium (YEP) [composition (\%,w/v): yeast extract (Difco) (1), peptone (Difco) (2), sugar (2)] for enzyme analyses, initial screening of mutants and fermentation trials. Sugars and other carbon sources were prepared as $20 \%$ stock solutions, filter-sterilized and added to the rest of the media, which was sterilized at $121{ }^{\circ} \mathrm{C}$ for $15 \mathrm{~min}$. The L-malic acid stock was adjusted to pH 6.0 with $\mathrm{KOH}$.

Isolation of glucose-negative strains. Strain P17-1A was grown to exponential phase on complete YNB-xylose medium and plated $\left(10^{7}-10^{8}\right.$ cells per plate) onto complete xylose medium supplemented with $6 \mathrm{mM}$ or $8 \mathrm{mM}-$ 2-deoxyglucose (Sigma). Mutants that were resistant to these levels of 2-deoxyglucose were further plated onto complete xylose medium supplemented with $30 \mathrm{mM}, 40 \mathrm{mM}$ or $80 \mathrm{~mm}$ 2-deoxyglucose. Mutants were tested for growth on solid media using various hexoses as carbon sources by replica-plating onto complete medium containing either D-glucose, D-mannose or D-fructose as the carbon source. The amount of growth was assessed visually at $12-24 \mathrm{hr}$ periods. Mutants showing a reduction of growth on any of these carbohydrates were further checked for stability of this characteristic.

Cells of strain D/X A were mutagenized with UV light. Cells, precultured on minimal YNB-glycerol, were grown in this medium to exponential phase. The cells were diluted in water and plated out (approximately $10^{3}$ cells per plate) onto YNB-glucose/xylose plates and exposed to UV light for $30 \mathrm{~s}$ and incubated in the dark at $30^{\circ} \mathrm{C}$ for 3-4 d. The survival rate was about 5\%. The fastest growing colonies were picked and cultured on YNB-glycerol and replica-plated onto YNB-glucose/xylose plates. Several fast-growing strains were checked for utilization of D-glucose and D-xylose in liquid YEP media.

Genetic techniques. The genetics of $P$. tannophilus have been described by James \& Zahab (1982, 1983). Haploid strains carrying auxotrophic markers were hybridized by plating on YM-YE media, incubating at $30^{\circ} \mathrm{C}$ for $4 \mathrm{~d}$, followed by incubation at $30^{\circ} \mathrm{C}$ on minimal media, with appearance of prototrophic colonies after $2 \mathrm{~d}$. The sporulation of diploid strains was achieved by incubation on YM for $4-5 \mathrm{~d}$ at $30^{\circ} \mathrm{C}$.

Enzyme analyses and chromatography of cell-free extracts. Methods used to prepare cell-free extracts and to measure the activities of hexokinase (EC 2.7.1.1), phosphoglucose isomerase (EC 5.3.1 .9), glucose-6-phosphate dehydrogenase (EC 1.1.1.49), xylose reductase (EC 1.1.1.21) and xylitol dehydrogenase (EC 1.1.1.9) enzymes are described in the accompanying paper (Wedlock \& Thornton, 1989).

Cell-free extracts were prepared for chromatography as described by Wedlock \& Thornton (1989) except that the cells were suspended in $50 \mathrm{mM}$-potassium phosphate buffer, $\mathrm{pH} 7 \cdot 5$, containing either 0.2 or $2 \mathrm{mM}-\mathrm{PMSF}$ prior to breakage. Extracts were desalted by passage through a Sephadex G-25 column (Wedlock \& Thornton, 1989) or by overnight dialysis against $10 \mathrm{~mm}$-potassium phosphate buffer, $\mathrm{pH} 7.5$. The extract (15 units D-glucose phosphorylating activity) was chromatographed on a $1.6 \times 20 \mathrm{~cm}$ DEAE-cellulose column (Whatman DE-52) equilibrated with the same buffer containing $2 \mathrm{mM}$-PMSF. The column was washed with two column volumes of buffer and the enzyme eluted with $250 \mathrm{ml}$ of a $0-0 \cdot 2 \mathrm{M}-\mathrm{NaCl}$ gradient at a flow rate of $30 \mathrm{ml} \mathrm{h}^{-1}$. Fractions $(5 \mathrm{ml})$ were collected and the D-glucose- and D-fructose-phosphorylating activities measured. The shape of the gradient was checked with a conductivity meter.

Analysis of cell-free extracts by HPLC. The enzymic conversion of D-glucose and sorbitol by cell-free extracts, in in vitro reaction mixtures, was followed by HPLC. Reaction mixtures ( $1 \mathrm{ml}$ total volume) contained $50 \mathrm{mM}$ D-glucose or sorbitol, $50 \mathrm{~mm}$-cofactor (NADPH or $\mathrm{NAD}^{+}$or NADPH and $\mathrm{NAD}^{+}, \mathrm{pH} 7 \cdot 0$ ), $100 \mathrm{~mm}-\mathrm{Tris} / \mathrm{HCl}$ buffer, $\mathrm{pH} 7 \cdot 0$, and extract ( $3 \mathrm{mg}$ protein) which had been dialysed against $10 \mathrm{mM}-\mathrm{Tris} / \mathrm{HCl}, \mathrm{pH} \mathrm{7.0}$, prior to use. Samples $(0.45 \mathrm{ml})$ were removed at zero time and after $24 \mathrm{~h}$ incubation at $30^{\circ} \mathrm{C}$. Protein was precipitated by the addition of $10 \mu \mathrm{TCA}(50 \%, \mathrm{w} / \mathrm{v})$, the samples centrifuged in an Eppendorf microfuge at $12,000 \mathrm{~g}$ for $10 \mathrm{~min}$ and frozen at $-20^{\circ} \mathrm{C}$ until required for HPLC analysis. Controls lacked either cofactor or extract.

\section{RESULTS AND DISCUSSION}

\section{Isolation of glucose-negative mutants}

Initially, mutants resistant to $8 \mathrm{~mm}$-2-deoxyglucose were isolated. Growth on D-xylose, D-glucose and D-fructose was similar to the wild-type but was greatly reduced on D-mannose. A $2: 2$ segregation both for growth on D-mannose and for resistance to $10 \mathrm{~mm}$-2-deoxyglucose was observed when diploids of crosses of two of these strains with P471-5D ade2 were sporulated. This segregation pattern suggested mutation in a single gene which was designated $h x k 2$.

A further set of mutants, which exhibited reduced growth on both D-glucose and D-mannose and was resistant to $40 \mathrm{~mm}$-2-deoxyglucose, was isolated. This additional lesion responsible for reduced growth on D-glucose was designated glu 1 . Crosses of these strains with P471-5D ade2 give the diploids P509 and P510. Three segregants, P509-3C $h x k 2$, P510-5A glu1 and P509-1B $h x k 2$ glul, mutant at either one or two independent loci, were recovered. The resistance of these strains to 2-deoxyglucose is shown in Table 1. The wild-type strains, P444-3D and P510-5A were 
Table 1. Resistance of strains to 2-deoxyglucose

+ , Good growth observed within 1-3d; $(+)$, inhibition of growth; - , no growth.

\begin{tabular}{|c|c|c|c|c|c|c|c|}
\hline \multirow[b]{3}{*}{ Strain/genotype } & \multicolumn{7}{|c|}{ Growth on D-xylose $(2 \%, w / v)$} \\
\hline & \multicolumn{7}{|c|}{ 2-Deoxyglucose concn (mM): } \\
\hline & 2 & 4 & 10 & 20 & 40 & 80 & 120 \\
\hline P444-3D (wild-type) & + & $(+)$ & - & - & - & - & - \\
\hline P510-5A (glul) & + & $(+)$ & - & - & - & - & - \\
\hline P509-3C (hxk2) & + & + & $(+)$ & - & - & - & - \\
\hline P509-1 B (hxk2 glu1) & + & + & + & + & $(+)$ & $(+)$ & $(+)$ \\
\hline $\mathrm{D} / \mathrm{X} \mathrm{A}(h x k 1 h x k 2 g l u 1)$ & + & + & + & + & + & + & + \\
\hline
\end{tabular}

Table 2. Growth of the wild-type and mutants of P. tannophilus on different carbon sources

+ , Confluent growth after $2 \mathrm{~d} ;+/-$, growth evident after $3-4 \mathrm{~d} ;-$, , no growth after $6 \mathrm{~d}$.

\begin{tabular}{lcccc} 
& \multicolumn{4}{c}{ Growth (minimal YNB plates, $30^{\circ} \mathrm{C}$ ) on: } \\
\cline { 2 - 5 } \multicolumn{1}{c}{ Strain/genotype } & D-Xylose & D-Glucose & D-Mannose & D-Fructose \\
P444-3D (wild-type) & + & + & + & + \\
P510-5A (glu1) & + & + & + & + \\
P509-3C $(h x k 2)$ & + & + & $+1-$ & + \\
P509-1B $(h x k 2$ glu1) & + & - & - & $+1-$ \\
D/X A $(h x k 1$ hxk glu1) & + & - & - & -
\end{tabular}

inhibited at $4 \mathrm{~mm}$, while strains P509-3C and P509-1B were able to grow relatively well in the presence of $4 \mathrm{~mm}$ and $20 \mathrm{~mm}$-2-deoxyglucose, respectively.

A third phenotypically distinct mutant was obtained by selecting for increased resistance to 2-deoxyglucose in liquid media. Although the segregant P509-1B was apparently capable of growth on solid YNB-xylose supplemented with $40 \mathrm{~mm}$-2-deoxyglucose, only slow growth was found to occur in liquid medium at this concentration of analogue. Growth ceased after $24 \mathrm{~h}$ but resumed after about $96 \mathrm{~h}$ of further incubation. Two mutant strains were isolated from two independent cultures. These strains had identical growth and sugar utilization characteristics. One of these strains, D/X A, was studied further; it was capable of normal growth in the presence of $40 \mathrm{~mm}$-2-deoxyglucose and a slightly reduced rate of growth at $120 \mathrm{~mm}$. From this strain, a further mutant was derived, by treatment with UV light and selecting for rapid growth on YEP-glucose/xylose medium. This latter strain was designated F/G 2.

\section{Growth and sugar utilization}

The growth of the wild-type and four 2-deoxyglucose-resistant mutant strains on a number of carbon sources is summarized in Table 2. Growth of strains P510-5A and P509-3C differed little from the wild-type except that P509-3C exhibited greatly reduced growth on D-mannose. Strains P509-1B and D/X A exhibited the most reduction in growth and were unable to grow on D-mannose and D-glucose. Growth on D-fructose was slow with the former strain but was evident after incubation for 3-4 d. The latter strain did not grow on D-fructose. Neither P509-1B nor D/X A utilized D-glucose when the wild-type and the four mutants were inoculated into YNBglucose at the standard cell density level $(0.5 \mathrm{ml}$ inoculum of OD 34-36 at $600 \mathrm{~nm})$. At a high cell density ( $10 \mathrm{ml}$ inoculum of OD 34-36 at $600 \mathrm{~nm}$ ) strain P509-1B grew and utilized glucose more slowly than the wild-type (Fig. $1 a, b$ ). Strain D/X A did not grow when inoculated at high cell density, but there was a slow apparent utilization of glucose (Fig. $1 a, b$ ). Most of the D-glucose consumption was accounted for by the conversion of D-glucose to D-fructose. After $96 \mathrm{~h}, 3.3 \mathrm{~g}$ glucose $1^{-1}$ had been consumed and $2.4 \mathrm{~g}$ fructose $1^{-1}$ had accumulated in the medium. 

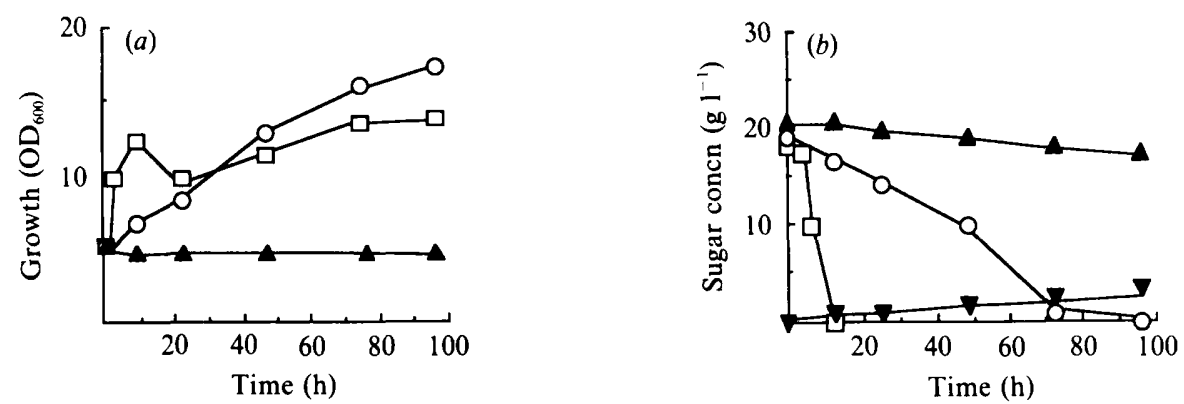

Fig. 1. (a) Growth of the wild-type, P444-3D ( $\square$ ) and mutants P509-1 B (O) and D/X A (ム) on D-glucose $(2 \%, w / v)$ at high cell density. $(b)$ Utilization of $D-g l u c o s e ~(2 \%, w / v)$ at high cell density by the wild-type, P444-3D ( $\square$ ) and mutants P509-1B (O) and D/X A (A). V, D-Fructose production by strain D/X A.

The identity of the fructose was confirmed by HPLC separation followed by reduction with sodium borohydride (P. Bicho, personal communication). An approximate 1:1 ratio of sorbitol and D-mannitol was obtained after reduction with sodium borohydride, as would be expected from the reduction of D-fructose. Further confirmation was by ${ }^{13} \mathrm{C}-\mathrm{NMR}$ (P. Bicho, personal communication).

The conversion of D-glucose to D-fructose was thought to be catalysed by the xylose pathway enzymes, xylose reductase and xylitol dehydrogenase, which are known to have broad substrate specificities (Ditzelmuller et al., 1984a, b; Morimoto et al., 1986, 1987). D-Glucose could be converted by a reduction step to sorbitol, catalysed by xylose reductase, and then oxidized to D-fructose, catalysed by xylitol dehydrogenase. To test this hypothesis we examined cell-free extracts, prepared from strain $\mathrm{D} / \mathrm{X} \mathrm{A}$, for the conversion of D-glucose and sorbitol to $\mathrm{D}$-fructose in vitro. When the extract was incubated with D-glucose in the presence of NADPH and NAD ${ }^{+}$, a small amount of $\mathrm{D}$-fructose was detected after $24 \mathrm{~h}$ incubation. A small amount of sorbitol was detected when NADPH alone was used as the cofactor. The conversion of sorbitol to D-fructose, with $\mathrm{NAD}^{+}$as the cofactor, was readily observed and more than $50 \%$ was converted during the $24 \mathrm{~h}$ period. These results agreed with enzyme analyses done on the cell-free extracts of strain $\mathrm{D} / \mathrm{X} \mathrm{A}$. When D-glucose was used as a substrate, the NADPH-dependent reductase activity was about $6 \%$ of the activity measured with D-xylose. Approximately $71 \%$ of the $\mathrm{NAD}^{+}$-dependent activity with xylitol was measured when sorbitol was substituted. These observations are consistent with the proposition that D-glucose can be converted to D-fructose by xylose pathway enzymes. Furthermore, a mutant defective in the xylitol dehydrogenase enzyme and unable to grow on D-xylose, although normal for growth on D-glucose, cannot grow on sorbitol. Mutants such as $\mathrm{D} / \mathrm{X} \mathrm{A}$, defective in all three hexokinases, have lost the ability to grow on sorbitol also. Although the sorbitol presumably could be converted to D-fructose in these strains, subsequent metabolism of the D-fructose is blocked by the lesions within the hexokinase genes.

\section{Growth in media containing two carbon sources}

All the mutant strains with the exception of $D / X$ A and F/G 2 were found to utilize D-glucose readily when inoculated into media containing both D-glucose and $D$-xylose. The wild-type strain and mutant strains P510-5A and P509-3C utilized the D-glucose preferentially, D-xylose utilization only commencing after most of the D-glucose was utilized. Mutant P509-1B was found to utilize D-glucose and D-xylose simultaneously when inoculated into minimal YNBglucose/xylose at the standard cell density. The 'co-utilization' of D-glucose and D-xylose by this strain was also found to occur in media which contained either D-glucose and glycerol or D-glucose and L-malic acid as carbon sources. D-Glucose utilization by P509-1B was slow initially, but after $48 \mathrm{~h}$ was faster than the rate of $\mathrm{D}$-xylose utilization, which was inhibited. At least part of this observed utilization was due to the larger population of cells present in the media after growth on D-xylose or glycerol had occurred. The D-glucose was converted to ethanol, since the ethanol concentration in the medium was greater than the amount produced from the fermentation of $D$-xylose as a sole carbon source. 


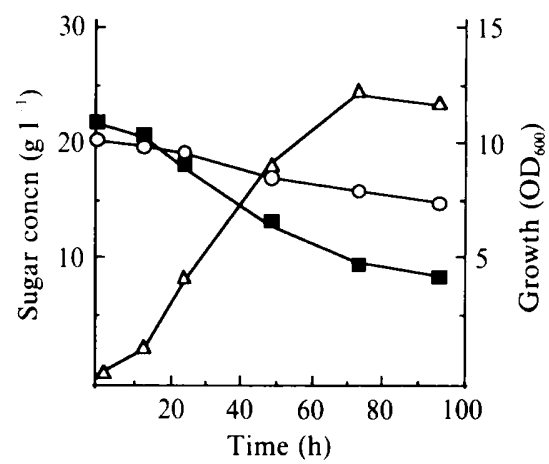

Fig. 2

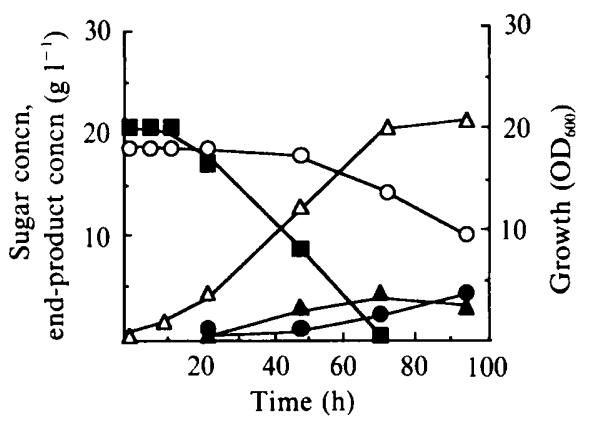

Fig. 3

Fig. 2. Utilization of D-glucose and D-xylose (both $2 \%, w / v)$ by strain D/X A in YNB media. O, D-glucose; $\mathbf{\square}$, D-xylose; $\triangle$, growth.

Fig. 3. Fermentation of D-glucose and D-xylose (both $2 \%$, w/v) by strain F/G 2 in YEP media. O, D-glucose; $\mathbf{\square}$, D-xylose; $\bullet$, D-fructose; $\boldsymbol{\Delta}$, ethanol; $\Delta$, growth.

Table 3. Hexokinase, phosphoglucose isomerase and D-glucose-6-phosphate dehydrogenase activities of wild-type and mutants

For each assay, the strains were grown in YEP-glucose/xylose (both $2 \%$, w/v) for $42 \mathrm{~h}$, except that for the hexokinase assay, P444-3D, P510-5A and P509-3C were grown in YEP-glucose (2\%, w/v) for $42 \mathrm{~h}$.

Specific activity

[ $\mu \mathrm{mol}$ NADP reduced $\mathrm{min}^{-1}$ (mg protein) $)^{-1}$ ]

Strain/genotype

P444-3D (wild-type)

P510-5A ( $g l u 1)$

P509-3C (hxk2)

P509-1B (hxk2 glu1)

D/X A $(h x k 1 h x k 2 g l u 1)$

\begin{tabular}{|c|c|c|c|}
\hline \multicolumn{4}{|c|}{$\begin{array}{c}\text { Specific activity } \\
{\left[\mu \mathrm{mol} \text { NADP reduced } \mathrm{min}^{-1}(\mathrm{mg} \text { protein })^{-1}\right]}\end{array}$} \\
\hline \multicolumn{2}{|c|}{ Hexokinase } & \multirow[b]{2}{*}{$\begin{array}{l}\text { Phosphoglucose } \\
\text { isomerase }\end{array}$} & \multirow[b]{2}{*}{$\begin{array}{l}\text { Glucose-6-phosphate } \\
\text { dehydrogenase }\end{array}$} \\
\hline $\begin{array}{l}\text { D-Glucose } \\
\text { as substrate }\end{array}$ & $\begin{array}{l}\text { D-Fructose } \\
\text { as substrate }\end{array}$ & & \\
\hline 0.80 & 0.87 & $3 \cdot 3$ & $0 \cdot 17$ \\
\hline 0.63 & 0.78 & $4 \cdot 4$ & $0 \cdot 12$ \\
\hline 0.38 & $0 \cdot 11$ & 3.9 & 0.24 \\
\hline 0.050 & $0 \cdot 15$ & $2 \cdot 0$ & 0.31 \\
\hline 0.0061 & 0.0096 & $1 \cdot 1$ & $0 \cdot 34$ \\
\hline
\end{tabular}

A different pattern of sugar utilization was displayed by mutant $\mathrm{D} / \mathrm{X}$ A. D-Glucose utilization in the minimal YNB-glucose/xylose media by this strain was greatly reduced but utilization of the D-xylose was markedly inhibited (Fig. 2). The utilization of D-xylose slowed after $72 \mathrm{~h}$ incubation, whereas the sugar was typically almost completely utilized at this time when presented as the sole carbon source. Strain F/G 2, which was derived from D/X A and presently uncharacterized, showed negligible $D$-glucose utilization when inoculated into the same minimal YNB-glucose/xylose medium, but utilization of the D-xylose was incomplete. However, in YEP-glucose/xylose medium, there was complete utilization of the D-xylose to ethanol (Fig. 3). The maximum ethanol concentration in the medium reached $4 \cdot 1 \mathrm{~g}^{-1}$, with a yield of $0.19 \mathrm{~g}$ per $\mathrm{g}$ sugar consumed. D-Glucose utilization was minimal until $48 \mathrm{~h}$, after which D-fructose started to appear in the medium. At the point of maximum ethanol concentration $\left(72 \mathrm{~h}\right.$ ), only $3.0 \mathrm{~g} \mathrm{D}$-glucose $\mathrm{l}^{-1}$ had been consumed, whereas all the D-xylose had been depleted. Further work is continuing to determine the suitability of this mutant to ferment $D$-xylose in mixtures of D-glucose and D-xylose.

\section{Enzyme activities and chromatography of cell-free extracts}

Hexokinase, phosphoglucose isomerase and glucose-6-phosphate dehydrogenase activities were measured in the mutants and compared with the wild-type activities (Table 3). Small 
reductions of D-glucose-phosphorylating activity were seen with mutants defective in one gene. The double mutant, P509-1B, exhibited only about $6 \%$ of the wild-type activity on D-glucose; greater activity was measured with D-fructose as the substrate. This correlated with the ability of strain P509-1 B to grow slowly on D-fructose. Strain D/X A had the lowest measured hexokinase activity, both with D-glucose and D-fructose as the substrate. Although phosphoglucose isomerase and glucose-6-phosphate dehydrogenase activities did vary between the mutants and the wild-type, the differences were not great. This further supported the view that the resistance of the mutants to 2-deoxyglucose was due to mutations within the hexokinase genes.

Cell-free extracts prepared from the wild-type strain and each of the mutants were chromatographed on DEAE-cellulose. The wild-type extracts were desalted by filtration on Sephadex G-25, whereas extracts prepared from the mutants were desalted by dialysis. Three major peaks of hexose-phosphorylating activity were measured in extracts of the wild-type strain P444-3D (Fig. 4a). These peaks differed in their ratio of D-glucose to D-fructose phosphorylation $(\mathrm{F} / \mathrm{G})$ activity, being $3 \cdot 0 / 1 \cdot 0,0 \cdot 6 / 1 \cdot 0$ and $1 \cdot 2 / 1 \cdot 0$, respectively. These activities corresponded to hexokinase $\mathrm{B}$, a glucokinase and hexokinase $\mathrm{A}$, respectively. The latter two enzymes were only partially separated.

Cell-free extracts prepared from strains P510-5A, P509-3C, P509-1B and D/X A were also subjected to chromatography. Two hexose-phosphorylating enzymes were present in mutant P510-5A, with $\mathrm{F} / \mathrm{G}$ ratios of $3.0 / 1.0$ and $1 \cdot 3 / 1 \cdot 0$ (Fig. $4 b$ ). Hence, hexokinases $\mathrm{A}$ and $\mathrm{B}$ but not the glucokinase were active. In addition to hexokinase B, a glucokinase with activity specific to D-glucose was present in strain P509-3C (Fig. 4c). Both hexokinase A and the glucokinase were absent from the double mutant, P509-1 B, but hexokinase B (F/G ratio 3.0/1.0) was present (Fig. $4 d$ ). In order to chromatograph 5 units of D-glucose-phosphorylating activity from a cell-free extract of strain P509-1B about five times as much protein, compared to the wild-type extract, had to be loaded onto the column. Thus it would appear that this enzyme is present at only low levels in this yeast. Negligible activity of any of the three enzymes was measured when an extract of $\mathrm{D} / \mathrm{X} \mathrm{A}$ was chromatographed.

Chromatography of the wild-type extract, prepared from cells grown on either D-xylose or glycerol, revealed lower levels of hexokinase A compared with cells grown on D-glucose (Fig. $4 e$ ). The activities of hexokinase $\mathrm{B}$ and the glucokinase were similar in cells grown on all three carbon sources.

These results suggest some similarities to the enzymes found in $S$. cerevisiae. The latter possesses two hexokinases, PI and PII, with F/G ratios of $2 \cdot 5-3.5 / 1.0$ and $1 \cdot 0-1 \cdot 5 / 1 \cdot 0$, respectively (Ramel et al., 1971 ; Colowick, 1973; Barnard, 1975; Gancedo et al., 1977; Entian \& Mecke, 1982; Frohlich et al., 1984; Fernández et al., 1985) and a D-glucose specific glucokinase (Maitra, 1970; Gancedo et al., 1977). Both hexokinase PI and the glucokinase are constitutive, while the hexokinase PII isoenzyme is inducible. In S. cerevisiae the PII hexokinase enzyme constitutes the major hexose-phosphorylating activity within the cells during the exponential growth phase (Gancedo et al., 1977; Fernández et al., 1985). In $P$. tannophilus, both the glucokinase and the hexokinase $\mathrm{A}$ appeared to contribute the major activity. The glucokinase was constitutive, whereas the hexokinase A was inducible. The constitutive hexokinase B was only present at low levels and its sole presence within the cell could only support a slow rate of growth.

From results in this study, it appears probable that, in the absence of hexose:ATP-kinase activity, D-glucose is converted to sorbitol as a first step in the conversion of D-glucose to $D$-fructose. In the wild-type, D-glucose would follow the normal pathway of catabolism and none would be converted to sorbitol and D-fructose, since both xylose reductase and xylitol dehydrogenase are repressed by D-glucose (Maleszka et al., 1983; Bicho et al., 1988; Wedlock \& Thornton, 1989). The existence of such a pathway has important implications for the acquisition of glucose-negative strains capable of D-xylose utilization in the presence of D-glucose. In the accompanying paper (Wedlock \& Thornton, 1989) we demonstrated that xylose reductase and xylitol dehydrogenase are not repressed in mutants which are defective in hexokinase $A$. However, in this study, strain D/X A, which is defective in hexokinase A as well as hexokinase B and glucokinase, failed to efficiently utilize $\mathrm{D}$-xylose in a mixture of D-glucose and D-xylose. This 

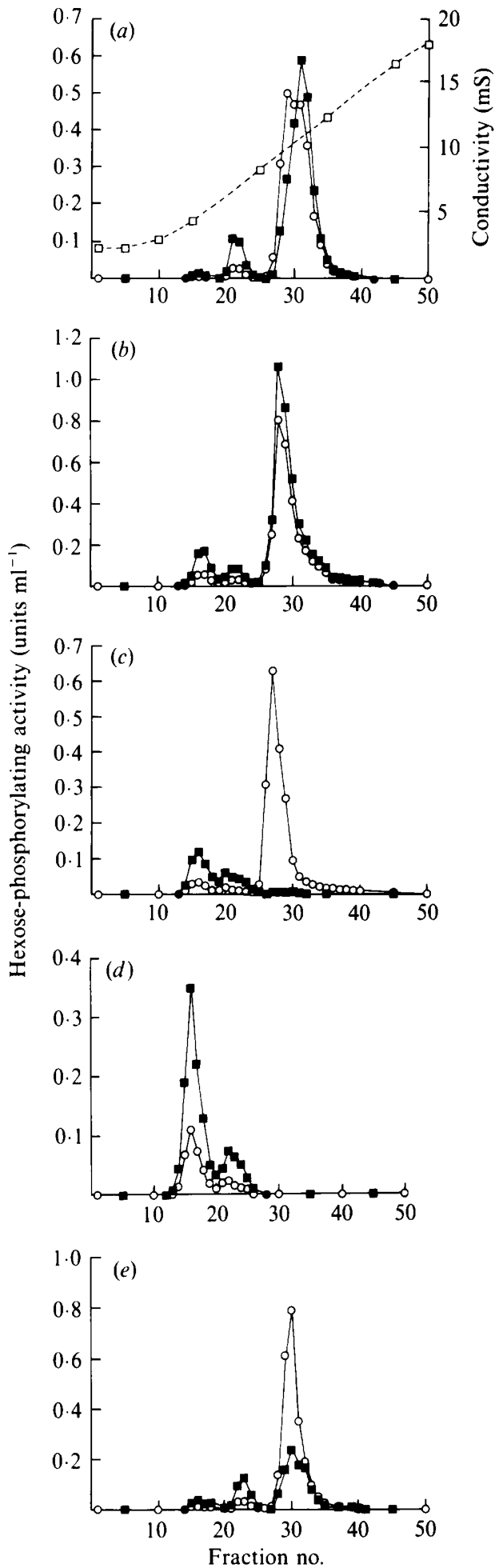

Fig. 4. DEAE-cellulose chromatography of cell-free extracts from the wild-type strain, P444-3D ( $a$, cells grown on D-glucose; $e$, cells grown on D-xylose), and mutants P510-5A (b), P509-3C (c) and P509-1B $(d)$. O, D-glucose-phosphorylation; $\mathbf{D}$, D-fructose phosphorylation; $\square$, conductivity. 
apparent inhibition of $D$-xylose utilization may be due to substrate competition for the xylose reductase and xylitol dehydrogenase enzymes and for NADPH and $\mathrm{NAD}^{+}$cofactors. Alternatively, D-glucose and D-xylose may compete for carrier-mediated transport into the cell. The inhibition of D-xylose utilization by D-glucose is alleviated in the F/G 2 mutant. The exact nature of the mutation conferring the ability to ferment $D$-xylose to ethanol in the presence of D-glucose needs to be investigated further.

We wish to thank Paul Bicho, Forest Research Institute, Rotorua, New Zealand for confirmation of the identity of D-fructose.

This work was supported by NZ Forest Research Institute contract no. 208, and NZ Energy Research Development Committee grant no. 3366.

\section{REFERENCES}

BARNARD, E. A. (1975). Hexokinases from yeast. Methods in Enzymology 42, 6-20.

Bicho, P. A., RunNals, P. L., Cunningham, J. D. \& LEE, H. (1988). Induction of xylose reductase and xylitol dehydrogenase activities in Pachysolen tannophilus and Pichia stipitis on mixed sugars. Applied and Environmental Microbiology 54, 50-54.

Colowick, S. P. (1973). The hexokinases. In The Enzymes, 3rd edn, vol. 9, pp. 1-48. Edited by P. D. Boyer. New York: Academic Press.

Ditzelmuller, G., KubiceK, C. P., Wohrer, W. \& RoHr, M. (1984a). Xylose metabolism in Pachysolen tannophilus: purification and properties of xylose reductase. Canadian Journal of Microbiology 30, 1330-1336.

Ditzelmuller, G., Kubicek, C. P., Wohrer, W. \& RoHR, M. (1984b). Xylitol dehydrogenase from Pachysolen tannophilus. FEMS Microbiology Letters 25, 195-198.

ENTIAN, K.-D. \& Mecke, D. (1982). Genetic evidence for a role of hexokinase isoenzyme PII in carbon catabolite repression in Saccharomyces cerevisiae. Journal of Biological Chemistry 257, 870-874.

Fernández, R., Herrero, P. \& Moreno, F. (1985). Inhibition and inactivation of glucose-phosphorylating enzymes from Saccharomyces cerevisiae by D-xylose. Journal of General Microbiology 131, 27052709.

Frohlich, K.-U., Entian, K.-D. \& MECKe, D. (1984). Cloning and restriction analysis of the hexokinase PII gene of the yeast Saccharomyces cerevisiae. Molecular and General Genetics 194, 144-148.

Gancedo, J., Clifton, D. \& Fraenkel, D. G. (1977). Yeast hexokinase mutants. Journal of Biological Chemistry 252, 4443-4444.

JAMES, A. P. \& ZaHAB, D. M. (1982). A genetic system for Pachysolen tannophilus, a pentose-fermenting yeast. Journal of General Microbiology 128, 22972301.
JAMES, A. P. \& ZAHAB, D. M. (1983). The construction and genetic analysis of polyploids and aneuploids of the pentose-fermenting yeast, Pachysolen tannophilus. Journal of General Microbiology 129, 24892494.

Lobo, Z. \& MaItra, P. K. (1977a). Resistance to 2-deoxyglucose in yeast : a direct selection of mutants lacking glucose-phosphorylating enzymes. Molecular and General Genetics 152, 297-300.

LOBO, Z. \& MaITRA, P. K. (1977b). Genetics of yeast hexokinase. Genetics 86, 727-744.

MaITRA, P. K. (1970). A glucokinase from Saccharomyces cerevisiae. Journal of Biological Chemistry 245, 2423-2431.

Maleszka, L. G., James, A. P., Rutten, H. \& SCHNEIDER, H. (1983). Xylitol dehydrogenase mutants of Pachysolen tannophilus and the role of xylitol in D-xylose catabolism. FEMS Microbiology Letters 17, 227-229.

Morimoto, S., Matsuo, M., Azuma, K. \& Sinskey, A. J. (1986). Purification and properties of D-xylulose reductase from Pachysolen tannophilus. Journal of Fermentation Technology 64, 219-225.

Morimoto, S., Takahiko, T., Azuma, K., Oshima, T. \& SinskeY, A. J. (1987). Purification and properties of aldose reductase from Pachysolen tannophilus. Journal of Fermentation Technology 65, 17-21.

Ramel, A. H., Rustrum, Y. M., Jones, J. G. \& BARNARD, E. A. (1971). Yeast hexokinase. IV. Multiple forms of hexokinase in the yeast cell. Biochemistry 10, 3499-3508.

Slininger, P. J., Bolen, P. L. \& Kurthman, C. P. (1987). Pachysolen tannophilus: properties and process considerations for ethanol production from D-xylose. Enzyme and Microbial Technology 9, 5-15.

Wedlock, D. N. \& Thornton, R. J. (1989). A hexokinase associated with catabolite repression in Pachysolen tannophilus. Journal of General Microbiology 135, 2013-2028. 